Rev Esp Casos Clin Med Intern (RECCMI). 2020 (Ago); 5(2): 96-99

\title{
Empiema por Streptococcus pyogenes como complicación de neumonía bilateral por SARS-CoV-2 (COVID-19)
}

\author{
Miguel Ángel Verdejo-Gómez', Gonzalo Rivas-Hernández², María Ruiz-Ruigómez', Laura Corbella-Vázquez \\ 'Servicio de Medicina Interna. Hospital Universitario 12 de Octubre. Madrid. España \\ ${ }_{2}^{2}$ Servicio de Microbiología y Parasitología. Hospital Universitario 12 de Octubre. Madrid. España
}

Recibido: $21 / 06 / 2020$

Aceptado: 05/08/2020

En línea: 31/08/2020

Citar como: Verdejo-Gómez MA, Rivas-Hernández G, Ruiz-Ruigómez M, Corbella-Vázquez L. Empiema por Streptococcus pyogenes como complicación de neumonía bilateral por SARS-CoV-2 (COVID-19). Rev Esp Casos Clin Med Intern (RECCMI). 2020 (Ago); 5(2): 96-99. doi: 10.32818/reccmi.a5n2a14.

Cite this as: Verdejo-Gómez MA, Rivas-Hernández G, Ruiz-Ruigómez M, Corbella-Vázquez L. Streptococcus pyogenes empyema as a complication of bilateral SARSCoV-2 pneumonia (COVID-19). Rev Esp Casos Clin Med Intern (RECCMI). 2020 (Ago); 5(2): 96-99. doi: 10.32818/reccmi.a5n2a14.

Autor para correspondencia: Miguel Ángel Verdejo-Gómez. mverdejo7@gmail.com

\section{Palabras clave}

$\triangleright$ SARS-COV-2

$\triangleright$ Neumonía

$\triangleright$ Empiema

$\triangleright$ Streptococcus pyogenes

\begin{abstract}
Resumen
El derrame pleural es una complicación habitual en la neumonía bacteriana y se describe en un 20-40\% de los pacientes hospitalizados. Su aparición en neumonía vírica es menos frecuente, así como la evolución a empiema. Presentamos el caso en una mujer de 63 años con neumonía bilateral por nuevo coronavirus SARS-CoV-2 asociada a derrame pleural derecho tipo exudado polimorfonuclear con criterios de empiema. Se aisló Streptococcus pyogenes (estreptococo grupo A) en líquido pleural. La paciente presentó una evolución favorable con antibioterapia dirigida y colocación de tubo de drenaje torácico. Durante su ingreso se diagnosticó incidentalmente una neoplasia mamaria.
\end{abstract}

\section{Keywords Abstract}

$\triangleright$ SARS-COV-2

$\triangleright$ Pneumonia

$\triangleright$ Empyema

$\triangleright$ Streptococcus pyogenes

\section{Puntos destacados}

$\triangleright$ La neumonía por SARS-CoV-2 puede asociar, como otras neumonías víricas, sobreinfección bacteriana, derrame pleural paraneumónico y empiema.

$\triangleright$ El diagnóstico precoz y el abordaje apropiado del empiema (antibioterapia dirigida y drenaje torácico) son fundamentales para asegurar una adecuada resolución clínica.

\section{Introducción}

El derrame pleural paraneumónico y el empiema son complicaciones habituales de la neumonía bacteriana. Entre un 20-40\% de los pacientes hospitalizados por neumonía presenta derrame pleural'. Sin embargo, la incidencia de esta complicación en pacientes con neumonía vírica es inferior; en el caso de la neumonía por SARS-CoV-2, se ha descrito en un 5,88\%², constituyendo la sobreinfección bacteriana una de sus posibles causas. Se cree que la alteración de los mecanismos inmunológicos producida por la infección vírica predispone al desarrollo de sobreinfección por otros microorganismos, tal y como se ha descrito en la infección por virus influenza ${ }^{3}$.

\section{Caso clínico}

\section{Antecedentes}

Mujer de 63 años, natural de Paraguay, trabajadora del hogar, residente en España desde hacía 10 años, sin viajes recientes fuera de Madrid. Como único antecedente personal destacaba pólipo hiperplásico endometrial y alto riesgo de cáncer de mama y ovario, en seguimiento especializado por 
antecedentes familiares. Describió además contacto reciente con una niña de 5 años con infección respiratoria de vías superiores. Acudía a Urgencias por infección respiratoria de 5 días de evolución consistente en febrícula $\left(37,5^{\circ} \mathrm{C}\right.$ en domicilio), tos no productiva, náuseas, cefalea, astenia y artromialgias. En las últimas 48 horas asociaba dolor pleurítico en región costal derecha y disnea progresiva hasta hacerse de mínimos esfuerzos, así como trepopnea derecha. No refería anosmia, ageusia o diarrea.

\section{Exploración física}

La paciente se encontraba bien hidratada y perfundida, afebril, taquipneica en reposo a $35 \mathrm{rpm}$ con saturación del 85\% respirando aire ambiente que ascendía al 99\% con mascarilla reservorio $\left(\mathrm{FiO}_{2} 1,0\right)$. En todo momento hemodinámicamente estable (tensión arterial 117/77 mmHg, frecuencia cardíaca 90 lpm). A la auscultación pulmonar destacaba hipofonesis marcada en base derecha con disminución de transmisión de vibraciones vocales junto con crepitantes en campo medio derecho y base izquierda. Se palpó una masa de consistencia pétrea de $3 \mathrm{~cm}$ de diámetro en cuadrante superoexterno de mama derecha, sin otros hallazgos en exploración física.

\section{Pruebas complementarias}

Se realizó analítica urgente que evidenció deterioro de función renal, elevación de reactantes de fase aguda, LDH y D-dímero, así como reducción de la actividad de protrombina (Tabla 1). La gasometría arterial mostró hipoxemia con alcalosis respiratoria.

La radiografía de tórax posteroanterior mostraba un infiltrado alveolointersticial tenue bilateral, más marcado en lóbulo superior izquierdo, junto con derrame pleural derecho con atelectasia de lóbulo inferior derecho asociada (Figura 1).

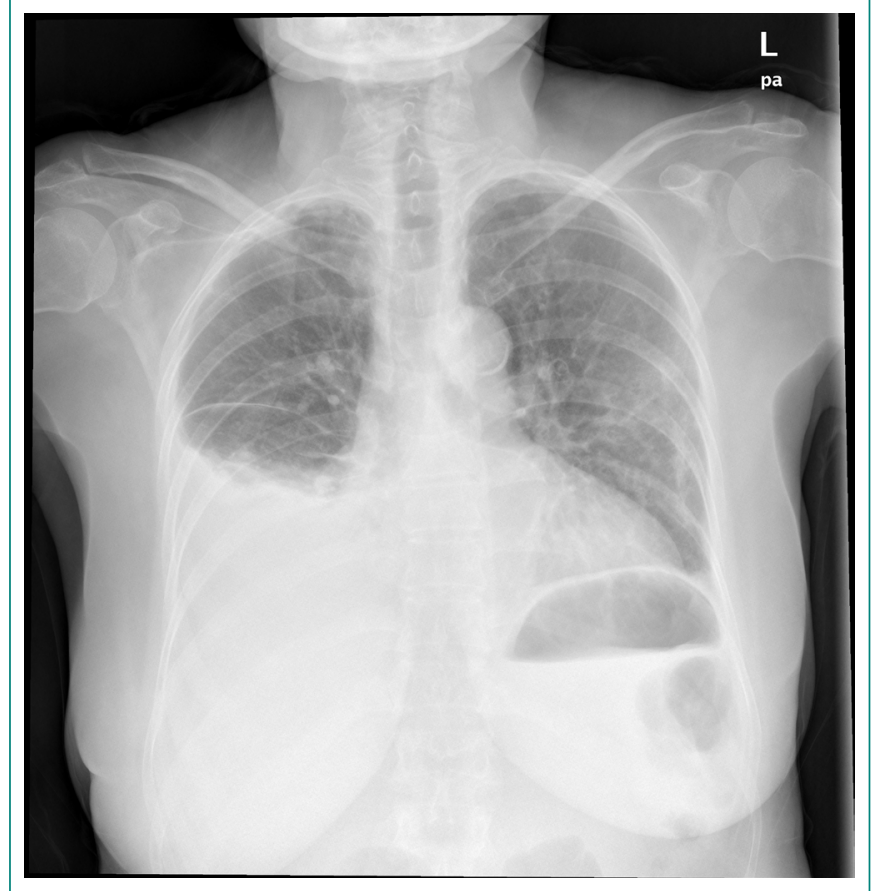

Figura 1. Radiografía de tórax posteroanterior

Ante la presencia de hipoxemia con alcalosis respiratoria, dolor pleurítico, derrame pleural unilateral y elevación de D-dímeros, en contexto epidemiológico de nuevo coronavirus SARS-CoV-2, se solicitó angio-TC de arterias pulmonares para descartar tromboembolismo. En escáner torácico observamos importante derrame pleural derecho parcialmente loculado que producía atelectasia

\begin{tabular}{|c|c|c|c|c|c|}
\hline \multicolumn{3}{|c|}{ Hemograma, bioquímica, hemostasia } & \multicolumn{3}{|c|}{ Líquido pleural } \\
\hline Parámetro & Valor & Referencia & Parámetro & Valor & Referencia \\
\hline Hemoglobina & $12,3 \mathrm{~g} / \mathrm{dl}$ & $13,0-16,8$ & Glucosa & $<2 \mathrm{mg} / \mathrm{dl}$ & $>60$ \\
\hline Plaquetas & $302.000 / \mu \mathrm{l}$ & $140.000-450.000$ & Proteínas & $3,8 \mathrm{~g} / \mathrm{dl}$ & $<3$ \\
\hline Leucocitos & $6.400 / \mu \mathrm{l}$ & $4.000-11.300$ & Cociente proteínas pleura/plasma & 0,59 & $<0,5$ \\
\hline Neutrófilos & $6.100 / \mu \mathrm{l}(95 \%)$ & $1.800-7.400$ & Lactato deshidrogenasa & $48.740 \mathrm{U} / \mathrm{l}$ & $<200$ \\
\hline Linfocitos & $300 / \mu l(4 \%)$ & $1.200-4.000$ & Cociente LDH pleura/plasma & 188 & $<0,6$ \\
\hline Creatinina & $1,41 \mathrm{mg} / \mathrm{dl}$ & $0,70-1,20$ & Hematíes & $9.522 / \mu \mathrm{l}$ & \\
\hline Sodio & $126 \mathrm{mEq} / \mathrm{l}$ & $136-145$ & Hematocrito & $1,1 \%$ & \\
\hline Potasio & $5,00 \mathrm{mEq} / \mathrm{l}$ & $3,50-5,10$ & Leucocitos & $221.735 / \mu \mathrm{l}$ & \\
\hline ALT (GPT) & $24 \mathrm{U} / \mathrm{I}$ & $5-45$ & Leucocitos polimorfonucleares & $60 \%$ & \\
\hline AST (GOT) & $31 \mathrm{U} / \mathrm{I}$ & $5-33$ & Leucocitos mononucleares & $40 \%$ & \\
\hline LDH & $249 \mathrm{U} / \mathrm{I}$ & $135-225$ & $\mathrm{pH}$ & 6,9 & $>7,2$ \\
\hline Proteína C reactiva & $60,37 \mathrm{mg} / \mathrm{dl}$ & $0,10-0,50$ & Ácido láctico & 11 & $<0,5$ \\
\hline Procalcitonina & $16,46 \mathrm{ng} / \mathrm{ml}$ & $<0,50$ & & & \\
\hline Actividad protrombina & $70 \%$ & $75-140$ & & & \\
\hline INR & 1,28 & $0,80-1,20$ & & & \\
\hline TTPa & $27 \mathrm{~s}$ & $26-39$ & & & \\
\hline Fibrinógeno & $1.268 \mathrm{mg} / \mathrm{dl}$ & $200-560$ & & & \\
\hline D-dímero & $7.646 \mathrm{ng} / \mathrm{ml}$ & $<500$ & & & \\
\hline
\end{tabular}

Tabla 1. Resultados de hemograma, bioquímica, hemostasia y análisis de líquido pleural 
completa de lóbulo inferior derecho, afectación en vidrio deslustrado de lóbulo superior izquierdo y masa hipercaptante en mama derecha sugestiva de malignidad (Figura 2).

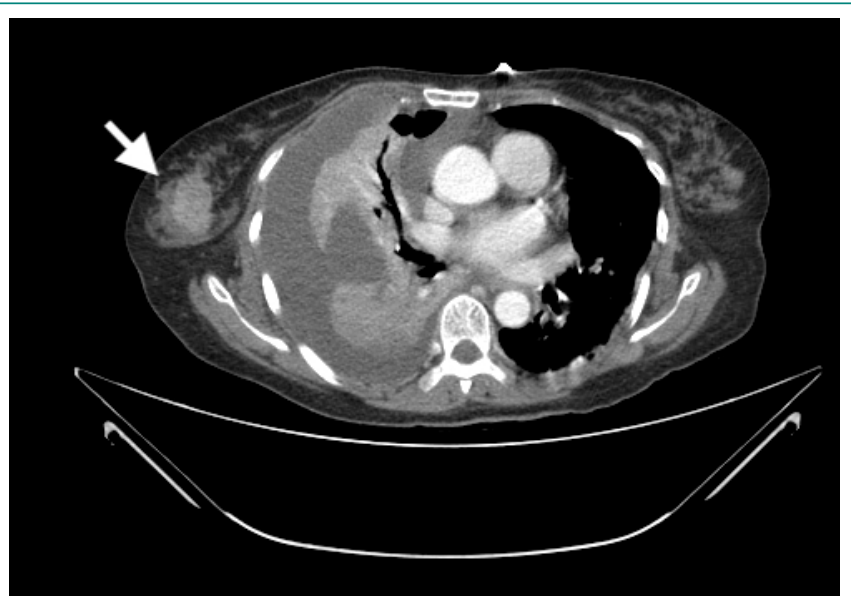

Figura 2.TC de tórax. Derrame pleural derecho con atelectasia y consolidación (broncograma aéreo) de lóbulo inferior derecho. Puede apreciarse lesión mamaria sugestiva de malignidad (flecha)

Una primera determinación RT-PCR de SARS-CoV-2 en exudado nasofaríngeo en Urgencias fue negativa, si bien, ante la sospecha clínica, se repitió a las 48 horas con resultado positivo. Los estudios microbiológicos complementarios (hemocultivos, antigenuria de Legionella) resultaron negativos. No fue posible obtener una muestra de esputo. De esta manera, se diagnosticó a la paciente de infección por nuevo coronavirus SARS-CoV-2 asociada a derrame pleural derecho loculado. Se completó el estudio mediante toracocentesis diagnóstica (Tabla 1) con extracción de líquido purulento con pH de 6,9; glucosa indetectable, y, en tinción de Gram, abundantes leucocitos polimorfonucleares con cocos grampositivos en cadenas intra y extracelulares, compatible con empiema por cocos grampositivos (Figura 3).

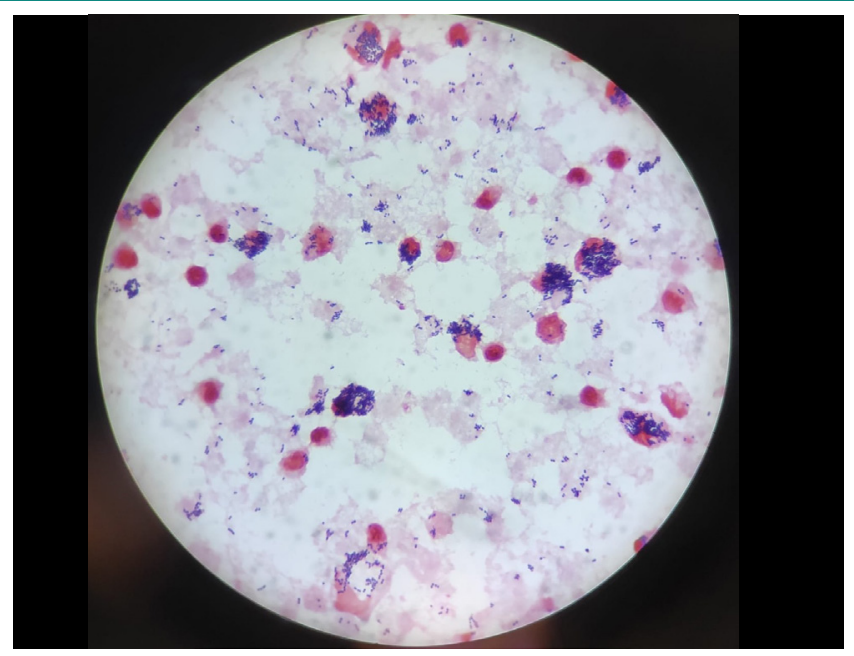

Figura 3. Tinción de Gram de líquido pleural. Abundantes leucocitos polimorfonucleares con cocos grampositivos en cadenas intra y extracelulares

Se inició tratamiento antibiótico empírico con ceftriaxona y clindamicina, y se procedió a la colocación de tubo de drenaje tipo pigtail con técnica Seldinger. Como tratamiento específico de COVID-19 la paciente recibió, según las re- comendaciones vigentes en el momento de su valoración, hidroxicloroquina (200 mg/12 h tras dosis de carga) y metilprednisolona (0,5 mg/kg/día) durante los primeros 5 días.

\section{Evolución}

La paciente presentó una evolución favorable: afebril durante su ingreso, con normalización de función renal y resolución progresiva de la insuficiencia respiratoria que permitió la retirada de la oxigenoterapia. Se retiró el drenaje torácico tras 1 semana de ingreso, con drenaje total de $700 \mathrm{ml}$ de líquido purulento. En cultivo de líquido pleural se aisló Streptococcus pyogenes (grupo A) sensible a penicilina $(\mathrm{CMI}<1)$, secuenciándose el tratamiento antibiótico dirigido por antibiograma a amoxicilina vía oral tras 7 días de tratamiento intravenoso. Completó el tratamiento antibiótico dirigido durante un total de 4 semanas.

Respecto a la lesión mamaria identificada en la TC de tórax, se confirmó su naturaleza maligna mediante mamografía y biopsia con aguja gruesa. Fue remitida a Ginecología para su posterior seguimiento y tratamiento oncológico.

\section{Diagnóstico}

Empiema por Streptococcus pyogenes como complicación de neumonía bilateral por SARS-CoV-2.

\section{Discusión y conclusiones}

La pandemia por el nuevo coronavirus SARS-CoV-2 ha tenido un impacto inconmensurable en nuestra sociedad y en nuestro sistema sanitario, con más de 250.000 casos y más de 28.000 fallecidos en España hasta julio de $2020^{4}$. El escenario de sobrecarga asistencial, la dificultad de acceso a exploraciones complementarias, como la ecografía clínica, por riesgo de contagio y transmisión, y el desconocimiento de las manifestaciones clínicas de esta nueva enfermedad dificultan el diagnóstico y tratamiento de complicaciones comunes como el derrame pleural complicado. La baja frecuencia de derrame pleural en el seno de la neumonía por SARS-CoV-2 ${ }^{2}$ nos obliga a establecer un alto índice de sospecha de complicación, con realización precoz de toracocentesis diagnóstica.

La coinfección bacteriana es una complicación conocida en diversas infecciones víricas respiratorias, como ocurre en la infección por virus de la gripe; las guías de práctica clínica recomiendan incluso el uso de antibioterapia empírica en caso de detección positiva para virus influenza $A^{5}$. Así se ha actuado en la neumonía COVID-19, según experiencias previas con otros coronavirus, como MERS, que asocian hasta un 18\% de sobreinfección bacteriana ${ }^{6}$. En la escasa experiencia clínica publicada hasta el momento, la tasa de coinfección bacteriana en COVID-19 varía desde el 0,6\% hasta el 45\%?, si bien únicamente se recogen estudios retrospectivos con gran heterogeneidad.

Respecto al microorganismo en cuestión, se han reportado casos de empiema por Streptococcus pyogenes sobre otros tipos de neumonía viral, concretamente en infección por virus influenza $\mathrm{A}^{3}$. Se postula que la alteración de los mecanismos inmunológicos producida por la infección viral podría predisponer a este tipo de infección piógena. Esto puede ser especialmente relevante en la infección por SARS-CoV-2, donde no sólo se ha descrito una desregulación del sistema inmune que conlleva un síndrome de respuesta inflamatoria y liberación de citocinas, sino que se han empleado múltiples fármacos inmunosupresores (corticoesteroides, anticuerpos monoclonales anti IL-6 o IL-1) que predisponen a infecciones bacterianas graves con expresión clínica larvada. 
En nuestro caso, la paciente recibió tratamiento con corticoesteroides, pero no otros inmunomoduladores.

El hallazgo incidental de una neoplasia maligna, factor predisponente de infección complicada y de peor evolución en pacientes con COVID-19, evidencia la necesidad de mantener los procedimientos clínico-terapéuticos fundamentales más allá del abordaje de la infección por SARS-CoV-2, aun encontrándonos en esta situación epidemiológica tan complejå ${ }^{8}$. En este caso fue posible un diagnóstico y tratamiento oncológico precoz.

Hasta donde sabemos, éste es el primer caso de empiema por Streptococcus pyogenes asociado a neumonía por SARS-CoV-2 que se describe en la bibliografía.

\section{Bibliografía}

1. Light RW. Parapneumonic effusions and empyema. Proc Am Thorac Soc 2006; 3(1): 75-80. doi: 10.1513/pats.200510-113JH.

2. Bao C, Liu X, Zhang H, LiY, Liu J. Coronavirus disease 2019 (COVID-19) CT findings: a systematic review and meta-analysis. J Am Coll Radiol. 2020; 17(6) 701-709. doi: 10.1016/j.jacr.2020.03.006.
3. Asai $N$, Suematsu $H$, Sakanashi $D$, Kato $H$, Hagihara M, Watanabe $H$, et al. A severe case of Streptococcal pyogenes empyema following influenza A infection. BMC Pulm Med. 2019; 19(1): 25. doi: 10.1186/s12890-019-0787-9.

4. Actualización no 155. Enfermedad por el coronavirus (COVID-19) (Internet). Disponible en: https://www.mscbs.gob.es/profesionales/saludPublica/ccayes/alertas_Actual/nCov-China/documentos/Actualizacion_155_COVID-19. pdf (citado 4 de julio de 2020).

5. Metlay JP, Waterer GW, Long AC, Anzueto A, Brozek J, Crothers K, et al. Diagnosis and treatment of adults with community-acquired pneumonia. An Official Clinical Practice Guideline of the American Thoracic Society and Infectious Diseases Society of America. Am J Respir Crit Care Med. 2019; 200(7): e45-e67. doi: 10.1164/rccm.201908-1581ST.

6. Arabi YM, Al-Omari A, Mandourah Y, Al-Hameed F, Sindi AA, Alraddadi B, et al. Critically ill patients with the middle east respiratory syndrome: a multicenter retrospective cohort study. Crit Care Med. 2017; 45(10): 1683-1695. doi: 10.1097/CCM.0000000000002621.

7. Lai CC, Wang CY, Hsueh PR. Co-infections among patients with COVID-19: the need for combination therapy with non-anti-SARS-CoV-2 agents? J Microbiol Immunol Infect. 2020: S1684-1182(20)30127-4

8. Spring LM, Specht MC, Jiménez RB, Isakoff SJ, Wang GX, Ly A, et al. Case 222020: a 62-year-old woman with early breast cancer during the Covid-19 pandemic. N Engl J Med. 2020; 383(3): 262-272. doi: 10.1056/NEJMcpc2002422. 